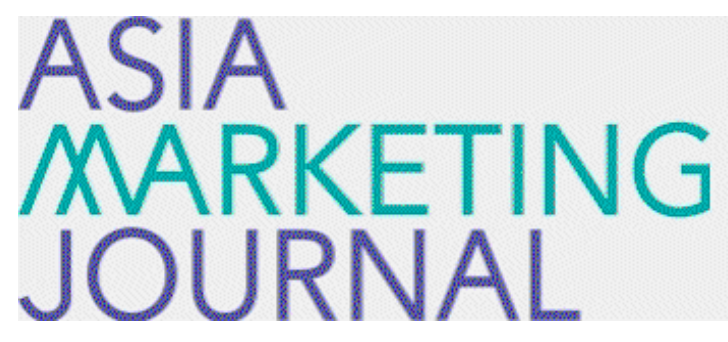

ASIA MARKETING JOURNAL

Volume 20 | Issue 2

Article 3

7-30-2018

\title{
Using Predictive Analytics to Profile Potential Adopters of Autonomous Vehicles
}

Eun-Ju Lee

Nordirov Zafarzon

Jing Zhang

Follow this and additional works at: https://amj.kma.re.kr/journal

Part of the Marketing Commons

\section{Recommended Citation}

Lee, Eun-Ju; Zafarzon, Nordirov; and Zhang, Jing (2018) "Using Predictive Analytics to Profile Potential Adopters of Autonomous Vehicles," Asia Marketing Journal: Vol. 20 : Iss. 2 , Article 3.

Available at: https://doi.org/10.15830/amj.2018.20.2.65

This Article is brought to you for free and open access by Asia Marketing Journal. It has been accepted for inclusion in Asia Marketing Journal by an authorized editor of Asia Marketing Journal. 


\title{
Using Predictive Analytics to Profile Potential Adopters of Autonomous Vehicles*
}

\author{
Eun-Ju Lee** \\ Nordirov Zafarzon*** \\ Jing Zhang****
}

\begin{abstract}
Technological advances are bringing autonomous vehicles to the ever-evolving transportation system. Anticipating adoption of these technologies by users is essential to vehicle manufacturers for making more precise production and marketing strategies. The research investigates regulatory focus and consumer innovativeness with consumers' adoption of autonomous vehicles (AVs) and to consumers' subsequent willingness to pay for AVs. An online questionnaire was fielded to confirm predictions, and regression analysis was conducted to verify the model's validity. The results show that a promotion focus does not have a significantly positive effect on the automation level at which consumers will adopt $\mathrm{AVs}$, but a prevention focus has a significantly positive effect on conditional AV adoption. Consumer innovativeness, consumers' novelty-seeking have a significantly positive relationship with high and full AV adoption, and consumers' independent decision-making has a significantly positive effect on full AV adoption. The higher the level of automation at which a consumer adopts AVs, the higher the willingness to pay for them. Finally, using a neural network and decision tree analyses, we show methods with which to describe three categories for potential adopters of AVs.
\end{abstract}

Key words: Consumer Adoption, Autonomous Vehicles, Neural Network Analysis, Decision Tree, Marketing Analytics

\footnotetext{
* This research is supported by Korea National Research Foundation (2015R1D1A1A01057848 and 2018R1A2B6004658) which was awarded on Eun-Ju Lee. Authors made equal contributions to this paper and are listed in alphabetical order.

** Professor, Sungkyunkwan University, Business School, Sungkyun Convergence Institute of Intelligence and Informatics (elee9@skku.edu)

*** Master Student, Business School, Sungkyunkwan University

**** Doctoral Student, Business School, Sungkyunkwan University (wenwen1004@skku.edu), Corresponding Author
} 


\section{Introduction}

Today's world is rapidly changing under technological advancements in all aspects of human life, but change is nothing new: our planet has witnessed significant transformations all along, but they increased in speed from the industrial era to the digital era. Such is particularly the case in the development of autonomous vehicles (AVs), which are developing at a much faster pace than predicted. Strong motivation to research the recent advancements in AVs comes from these cars' enormous potential to increase the productive use of time spent in a vehicle and to reduce crashes, congestion, energy consumption, and pollution. According to Evan (2012), the use of AVs will increase roadway capacity from 273 percent to 445 percent, resulting in significantly less traffic congestion (Hevelke \& Nida-Rümelin, 2015). AVs are expected to enhance mobility for the elderly, people with disabilities, and low-income citizens and to relieve travelers of driving and navigation chores, freeing commuting hours for leisure or work. Less fuel consumption, producing less air pollution and a lower carbon footprint from road travel is another advantage (Greenblatt \& Saxena, 2015). Using AVs significantly reduces the need for parking space in cities, freeing space for other public and private uses (Fernandes \& Nunes, 2012). AVs also facilitate new business models of mobility as a service, including car-sharing, e-hailing, ride-hailing services, real-time ridesharing, and other services of the sharing economy. Moreover, AVs contribute to reducing car ownership, as AVs may be substituted for the existing models of vehicle ownership and patterns of land use and may create new markets and economic opportunities (Hoogma, Kemp, Schot, \& Truffer, 2005).

Despite these advantages, AVs face many questions from policymakers, passengers, insurance companies, and other parties (Fagnant \& Kockelman, 2015), the answers to which will be influential in shaping the adoption and impact of these innovative cars. These questions arise from disputes concerning liability, the time required to turn the existing stock of vehicles from non-autonomous to autonomous, and individuals' resistance to forfeiting control of their cars (Lin, 2016). The safety of driverless cars, as once occurred with the introduction of elevators without operators, is one of the most salient concerns (Fernandes \& Nunes, 2012). Establishment and implementation of rules and regulations for self-driving cars may require considerable time and efforts, drivers will be inexperienced in driving when complex situations arise that require manual driving, and ethical problems will arise when an AV's software is forced during an unavoidable collision to choose among multiple harmful courses of action.

The technology of AVs will significantly change the transportation industry, and the implementation of increasing numbers of automatic 
functions will lead to completely autonomous vehicles in which the passengers will have no driving responsibilities. Besides the technology itself, most of which is available today, other issues that remain to be solved include building the infrastructure to serve this type of vehicle, implementing regulations, and dealing with matters of risk management. Accordingly, most research that has addressed the status of AVs has focused on the benefits, costs, and risks generated by the imminent transition from human-operated vehicles to AVs at the global level and has framed predictions and future trends in this field. Also, individual's perceptions could affect the decision-making process of adopting AVs. As mentioned above, the safety problem is a significant problem in AVs filed. Therefore, one's perception of preference to prevention or promotion is substantial variable changing consumer's decision making (Werth \& Foerster, 2007). Prevention focus perception lead to more risk-prevent behaviors involved. In contrast, promotion focus perception drive individuals challenge the risky behavior (Higgins, 2002). Meanwhile, AVs have different automatic degrees. It's also an extremely significant variable affecting consumer's adopting process of AVs. Thus, the research questions in this article are how a regulatory focus on promotion and prevention of consumer behavior affects the level of automation at which a consumer will adopt AVs; how consumers' innovativeness, novelty-seeking, and independent decision- making regulates the level of automation at which a consumer will adopt AVs; and how that level affects consumers' willingness to pay for AVs.

\section{Theoretical Background}

\subsection{Automatous levels and adoption}

The Society of Automotive Engineers (SAE), a globally active professional association and standards-developing organization for engineering professionals in various industries, provides a standard taxonomy and definitions for automated driving to simplify communication and facilitate collaboration in technical and policy domains. SAE International divided the automation level of AVs into six levels, from no automation to full automation (table 1). Level 0 is no automation, level 1 is driver assistance, level 2 is partial automation, and conditional automation is level 3, high automation is level 4, full automation is level 5. A crucial distinction is that between level 2, where the human driver performs part of the dynamic driving task (driving mood), and level 3, where the automated driving system conducts the entire dynamic driving task. These levels are descriptive rather than normative and technical rather than legal, and they imply no particular order regarding market introduction. 
〈Table 1〉 SAE Vehicle Automation Levels

\begin{tabular}{|c|c|c|c|c|c|c|}
\hline $\begin{array}{l}\text { SAE } \\
\text { Level }\end{array}$ & Name & Narrative definition & $\begin{array}{l}\text { Execution of } \\
\text { Steering and } \\
\text { Acceleration/ } \\
\text { Deceleration }\end{array}$ & $\begin{array}{l}\text { Monitoring of } \\
\text { Driving } \\
\text { Environment }\end{array}$ & $\begin{array}{l}\text { Fallback } \\
\text { Performance of } \\
\text { Dynamic } \\
\text { Driving Task }\end{array}$ & $\begin{array}{l}\text { System } \\
\text { Capability } \\
\text { (driving } \\
\text { modes) }\end{array}$ \\
\hline \multicolumn{7}{|c|}{ Human driver monitors the driving environment } \\
\hline 0 & $\begin{array}{c}\text { No } \\
\text { Automation }\end{array}$ & $\begin{array}{l}\text { Full-time performance by the human } \\
\text { driver of all aspects of the dynamic } \\
\text { driving task, even when enhanced by } \\
\text { warning or intervention systems }\end{array}$ & Human driver & Human driver & Human driver & N/A \\
\hline 1 & $\begin{array}{c}\text { Driver } \\
\text { Assistance }\end{array}$ & $\begin{array}{l}\text { Driving-mode-specific execution by a } \\
\text { driver-assistance system of either } \\
\text { steering or acceleration/deceleration } \\
\text { using information about the driving } \\
\text { environment and with the expectation } \\
\text { that the human driver performs all } \\
\text { remaining aspects of the dynamic } \\
\text { driving task }\end{array}$ & $\begin{array}{l}\text { Human driver } \\
\text { and system }\end{array}$ & Human driver & Human driver & $\begin{array}{l}\text { Some } \\
\text { driving } \\
\text { modes }\end{array}$ \\
\hline 2 & $\begin{array}{c}\text { Partial } \\
\text { Automation }\end{array}$ & $\begin{array}{l}\text { Driving-mode-specific execution by } \\
\text { one or more driver-assistance systems } \\
\text { of both steering and } \\
\text { acceleration/deceleration using } \\
\text { information about the driving } \\
\text { environment and with the expectation } \\
\text { that the human driver performs all } \\
\text { remaining aspects of the dynamic } \\
\text { driving task }\end{array}$ & System & Human driver & Human driver & $\begin{array}{l}\text { Some } \\
\text { driving } \\
\text { modes }\end{array}$ \\
\hline \multicolumn{7}{|c|}{ Automated driving system ("system") monitors the driving environment } \\
\hline 3 & $\begin{array}{l}\text { Conditional } \\
\text { Automation }\end{array}$ & $\begin{array}{l}\text { Driving-mode-specific performance by } \\
\text { an automated driving system of all } \\
\text { aspects of the dynamic driving task } \\
\text { with the expectation that the human } \\
\text { driver will respond appropriately to a } \\
\text { request to intervene }\end{array}$ & System & System & Human driver & $\begin{array}{l}\text { Some } \\
\text { driving } \\
\text { modes }\end{array}$ \\
\hline 4 & $\begin{array}{c}\text { High } \\
\text { Automation }\end{array}$ & $\begin{array}{l}\text { Driving-mode-specific performance by } \\
\text { an automated driving system of all } \\
\text { aspects of the dynamic driving task, } \\
\text { even if a human driver does not } \\
\text { respond appropriately to a request to } \\
\text { intervene }\end{array}$ & System & System & System & $\begin{array}{l}\text { Some } \\
\text { driving } \\
\text { modes }\end{array}$ \\
\hline 5 & $\begin{array}{c}\text { Full } \\
\text { Automation }\end{array}$ & $\begin{array}{l}\text { Full-time performance by an } \\
\text { automated driving system of all } \\
\text { aspects of the dynamic driving task } \\
\text { under all roadway and environmental } \\
\text { conditions that can be managed by a } \\
\text { human driver }\end{array}$ & System & System & System & $\begin{array}{l}\text { All driving } \\
\text { modes }\end{array}$ \\
\hline
\end{tabular}


The "elements" of a level of automation indicate minimum system capabilities for each level. A particular vehicle may have multiple driving-automation features such that it could operate at different levels depending on the features that are engaged. The "system" of a level of automation refers to the driver-assistance system, a combination of driver-assistance systems, or automated driving system. Level 0 , 1and 2 refer to that human driver monitors the driving environment, meanwhile, level 3,4 and 5 automated driving system monitors the driving environment Excluded are warning and momentary intervention systems, which do not automate any part of the dynamic driving task on a sustained basis and so do not change the human driver's role in performing the dynamic driving task.

\subsection{Regulatory focus}

Regulatory focus is a two-sided variable that indicates that a single individual can be socialized with both types of regulatory focus. An individual's interactions with things and people involve different types and times of regulatory focus (Higgins, 1998). An individual can acquire either a strong promotion focuses or a strong prevention focus or both, but whether individuals have only one or both types of strong regulatory focus is based on each regulatory focus's concerning a distinct type of desired end state and distinct types of pleasure and pain. The promotion focus, which is concerned with accomplishments, hopes, and aspirations (Crowe \& Higgins, 1997), adjusts the presence and absence of positive outcomes, so ideal(promotion) self-guides have a promotion focus. The prevention focus, which is related to safety, responsibilities, and obligations (Summerville \& Roese, 2008), adjusts the absence and presence of adverse outcomes, so ought(prevention) self-guides have a prevention focus. The promotion focus is associated with advancement, growth, and accomplishment, whereas a prevention focus is related to security, safety, and responsibility. Therefore, when individuals work on a difficult task (like the adoption of $\mathrm{AVS}$ ) or have experienced failure with current conventional vehicles, those with a promotion focus should perform better in adopting of AVs, and those with a prevention focus should quit the task more readily, opting to retain conventional vehicles. In addition, when individuals work to generate a number of alternatives, such as selecting different levels of vehicle automation, those with a promotion focus should create more distinct options, as they are more motivated to consider higher levels of autonomy in AVs, and those with a prevention focus should generate more repetitive alternatives, preferring conventional vehicles with lower levels of automation. Accordingly, hypotheses H1 and H2 are developed:

H1: A prevention focus has a significantly 
positive effect on conditional $A V$ adoption (level 3).

H2: A promotion focus has a significantly positive effect on high (level 4) and full $A V$ adoptions (level5)

\subsection{Consumer innovativeness}

Consumer innovativeness is closely associated with consumers' novelty-seeking (CNS) and consumer independent decision-making (CIDM). A high level of CNS accelerates the speed of the adoption process's early stages, whereas CIDM is associated only with later stages of automation (Manning, Bearden, \& Madden, 1995). Also, consumer innovativeness regarding CNS and CIDM is constructed in relation to the AV-adoption process through noveltyseeking, new product awareness, and new product trials (Manning, Bearden, \& Madden, 1995). Epstein (1979, 1980) and Lastovicka and Joachimsthaler (1988) recommended the procedures to develop behavioral indices of new product awareness and adoption.

Consistent with Hirschman's (1980) proposal, CNS should have a more significant impact on the initial stages of the new-product-adoption process than it does on the later stages. Consumers who are predisposed to novelty-seeking are expected to gain comparatively high levels of new product awareness, but CNS may not provide a basis for predicting that consumers with such high levels will be subject inclined to accept a trial. This proposition is related to Mudd's (1990) argument that a desire for novel information does not necessarily include a willingness to try new products at all. Simply put, CNS is likely to get the consumer started through the adoption process, but it may not have substantial effects on the later stages. Therefore, we formed the following hypothesis:

H3: CNS has a significantly positive association with a high level of automation in the $A V$ adoption process, but not with the conditional level of automation.

Midgley and Dowling's (1978) independent decision-making perspective of consumer innovativeness postulates that consumers' reliance on communicated experience in evaluating new products is instrumental in regulating their adoption behavior. Therefore, CIDM represents a new product evaluation tendency. As reflected in Klonglan and Coward's (1970) model of the adoption process, new product evaluation is closely linked with the decision to try a product. Therefore, the greater a consumer's independence in evaluating new products, the greater his or her propensity toward early trial. However, there is little reason to expect that CIDM, as a new product evaluation tendency, will influence the stages of the adoption process that precedes evaluation. This approach is supported by Gatignon and Robertson's (1985) proposition that "when personal influence is operative, it is 
interdependent with mass media and its effect is most pronounced at later stages of the adoption process." Therefore, we developed hypothesis $\mathrm{H} 4$ :

H4: CIDM is positively associated with the adopting $A V s$ at the full level of automation.

\subsection{Willingness to pay}

Willingness to Pay (WTP) for AVs is one of the most frequent topics in academics. Many investigations have confirmed a positive relationship between the level of WTP and the level of autonomy at which a consumer will adopt AVs. Several studies have confirmed the validity of model estimates of WTP for adopting level 4 automation and level 3 automation (Bansal, Kockelman, \& Singh, 2016). Research results indicated that male respondents with a larger number of children, who live in higher-income neighborhoods, and who drive alone for social trips are willing to pay more to add level 3 and level 4 automation to their next vehicles. In contrast, licensed drivers who live in more job-dense neighborhoods and who are familiar with car-sharing and ride-sharing companies are willing to pay less to add level 3 and level 4 automation to their next vehicles (Bansal, \& Kockelman, 2017). Perhaps individuals who are familiar with car-sharing and ridesharing would instead rely on low-cost AVs instead of buying a new vehicle with added automation technology. Individuals who travel more, who have higher annual vehicle miles traveled (VMT), or who live farther from their workplaces have higher WTP to add level 4 AVs but lower WTP for level 3 AVs. Perhaps the opposite signs but practical significance of both attributes for the WTP for level 3 and level 4 AVs reflects the individuals perceptions that they would be able to use their travel time for work, sleep, or other meaningful activities in a level $4 \mathrm{AV}$ but not in a level $3 \mathrm{AV}$.

All else being equal, older persons are predicted to have a significantly lower WTP for AVs because they are likely to be concerned about learning to use AVs and unlikely to trust these technologies. Practically significant and positive associations between the number of crashes experienced by an individual and their WTP for $\mathrm{AVs}$ indicates that such persons may be anticipating the safety benefits of AVs. A dedicated survey showed that respondents who drive alone for work trips have a significantly higher WTP for AVs, indicating the possibility of shifting commuters to AV fleets in the future.

Earlier work shows a significantly positive association between AV adoption and WTP for these technologies (Bansal \& Kockelman, 2017). Considering the high cost of AV development by car manufacturers, how willing consumers are to purchase these vehicles in the future is a significant concern. Therefore, we develop 
hypothesis $\mathrm{H} 5$ to find support for the results of previous studies:

H5: The higher the autonomy level at which a consumer is willing to adopt an $A V$, the higher that consumer's WTP for the AV.

The current research investigates the autonomy level at which consumers will adopt AVs as a dependent variable, and examines regulatory focuses (promotion and prevention) and consumer innovativeness (CNS and CIDM) as independent variables. At the same time, the AV autonomy level at which a consumer will adopt AVs becomes an independent variable that affects consumers' WTP for AVs. This conceptual model is presented in Figure 1.

We predict that a promotion focus has a significantly positive effect on the level of autonomy at which a consumer will adopt AVs, while a prevention focus has a significantly positive effect on that level when the driving system is controlled by the human, but a significantly negative effect when the driving system is controlled by automation. We also predict that consumer innovativeness has a significantly positive effect on the autonomy level at which AVs will be adopted and that, the higher the acceptable autonomy level, the higher the consumer's WTP for it.

\subsection{Study design}

\subsubsection{Regulatory focus}

The independent variables of promotion focus and prevention focus were measured with eleven questions each. The questions ask respondents to use a five-point Likert scale to indicate how frequently specific events have occurred in their lives.

\subsubsection{Consumer innovativeness}

Consumer innovativeness was measuring

〈Figure 1〉 Conceptual Research Model

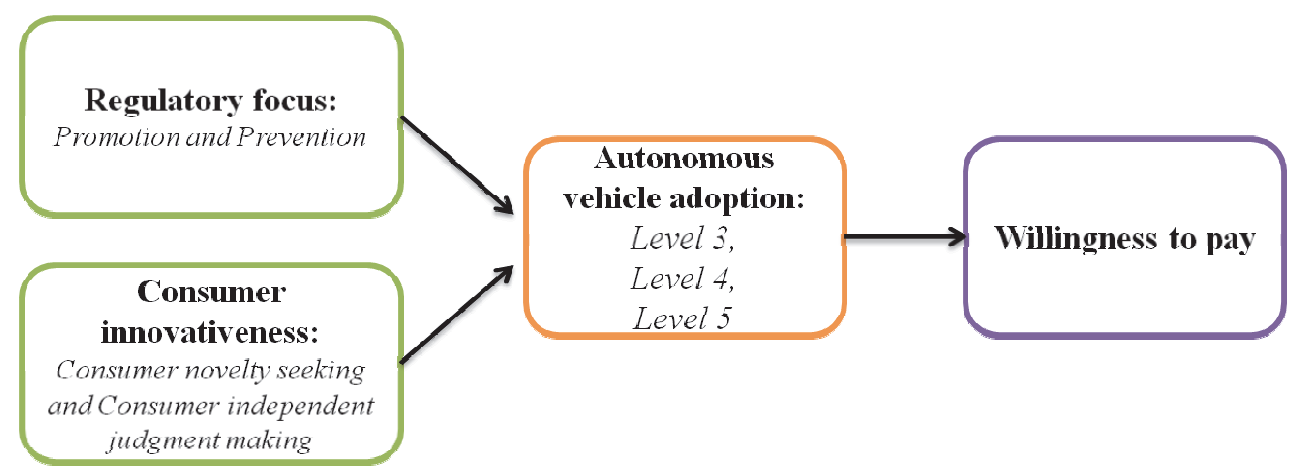

72 ASIA MARKETING JOURNAL Vol. 20 No. 02 July 2018 
using six- and seven-point scales. Besides, the items quoted from previous researches. The questionnaire measured CNS and CIDM, along with susceptibility to interpersonal influence (Bearden, Netemeyer, \& Teel, 1989), arousalseeking tendency (Mehrabian, 1978), and several demographic questions. The questionnaire was reduced to thirteen items over three fielding stages, and its validity and reliability were statistically established.

\subsubsection{AV adoption level}

The dependent variable of interest in the current study was the level of automation at which consumers will adopt AVs: conditional automation (level 3), high automation (level 4), and full automation (level 5). Level 3 is conditional automation, where execution of steering, acceleration/deceleration, and monitoring of the driving environment are automatically managed, but dynamic driving tasks are executed by the human driver. In high automation, level 4, all driving functions are delegated to automation, and only some driving modes are managed by the human driver. At level 5, full automation, all driving functions, and driving modes are executed automatically, with no human interaction. The questionnaire asked fifteen questions about all three levels of AV adoption, and respondents evaluated the statements using a seven-point Likert scale based on their expectations about AV adoption in the near future. We used clustering analysis to identify the three levels of adoption, levels 3, 4, and 5.

\subsubsection{Willingness to pay for AV adoption}

Survey respondents were asked to indicate the amount of money they are willing to pay for conditional, high, and full AV using a maximum of 20000 USD. The answers to the survey were further run in statistics to confirm or reject previous results, furthermore, to add new perspectives to this study.

\subsection{Sample and procedure}

Research on AVs is at the early stage and involves a large number of fields, including computer science, transportation, social science, and economics (Dautenhahn et al., 2009; Fischinger et al., 2014). Therefore, we use a qualitative method that includes various aspects of human life. We use an online questionnaire to develop theoretical elements of AV adoption and seek possible links between phenomena and concepts.

The questionnaire was distributed to respondents using social networks. Some respondents were recruited using a Mechanical Turk theoretical sampling group. From 306 responses, 252 answers were valid and subject to statistical analysis. The questionnaire was composed of questions about promotion focus and prevention focus and questions about consumer innovativeness 
to measure the respondents' levels of noveltyseeking and independent decision-making. After we confirmed our predictions, we used data from the questionnaire in a regression analysis to verify the validity of proposed model and hypotheses.

\section{Results and discussion}

The survey results were also analyzed using IBM SPSS. The survey explored fifteen aspects of the level of automation at which consumers will adopt AVs, a dependent variable in our research. We ran a factor analysis to reduce the information in a model by decreasing the dimensions of the observations.

This procedure simplified the data and reduced the number of significant dimensions to three: conditional autonomy (L3), high autonomy (L4), and full autonomy (L5). Further analyses were conducted on dependent variables that were derived from this factor reduction. This part of the research provides regression results to support or reject the model's proposed hypotheses. For H1, which predicts that a prevention focus has a significantly positive effect on conditional AV adoption, the results show that the coefficient estimate for prevention focus is positive and significant $(\beta=0.159, \mathrm{p}<$ 0.05), supporting H1.

For H2, which proposes that a promotion focus has a significantly positive effect on high and full AV adoptions, the results show that the coefficient estimate for promotion focus is positive but not significant $(\beta=0.117, p>0.05)$, so $\mathrm{H} 2$ is rejected. The result indicated that even

〈Table 2〉 Factor Analysis Results

\begin{tabular}{|l|c|c|c|}
\hline \multicolumn{1}{|c|}{ Items } & \multicolumn{3}{|c|}{ Factors } \\
\cline { 2 - 4 } & $\begin{array}{c}\text { Conditional } \\
\text { Adoption }\end{array}$ & $\begin{array}{c}\text { Full } \\
\text { Adoption }\end{array}$ & $\begin{array}{c}\text { High-Level } \\
\text { Adoption }\end{array}$ \\
\hline AV is better than human drivers. & .021 & .799 & .236 \\
AV is safer than human drivers. & -.064 & .841 & .261 \\
AV is better than human drivers for important trips. & -.086 & .868 & .033 \\
I have a favorable attitude toward autonomous devices. & .226 & .150 & .750 \\
I will recover control if I don't like an AV. & .159 & .092 & .831 \\
I will delegate control to an AV if I am drunk. & -.058 & .267 & .766 \\
I will not let an AV drive when passengers are inside. & .765 & .149 & .106 \\
I will not use an AV in the city. & .778 & -.115 & -.053 \\
I hate to lose the control/pleasure of driving to an AV. & .834 & -.053 & .156 \\
I prefer human driving to an AV because of risk. & .755 & -.121 & .157 \\
\hline
\end{tabular}


individuals have the preference for promotionfocus, they still have a doubting attitude towards to high (level 4) and full AV (level 5). Even if automatic vehicles have been widely used, full-scale automatic vehicles (level 4 and level 5) still cannot be fully accepted in people's existing cognition.

For H3, which proposes that CNS has a significantly positive association with AV adoption at a high level of autonomy but not a conditional level of autonomy, the results show that the coefficient estimate for CNS is positive and significant $(\beta=0.191, p<0.005)$, indicating that CNS has a significantly positive effect on AV adoption at a high level of autonomy and supporting H3.

For H4, which posits that CIDM has a significantly positive association with AV adoption at a full level of autonomy, the results show that the coefficient estimate for CIDM is positive and significant $(\beta=0.323, p<0.001)$, supporting $\mathrm{H} 4$.

For H5, which postulates that AV adoption at higher levels of autonomy is positively related to WTP, the results confirm that the coefficient estimates of WTP for conditional (L3) and full (L5) autonomy, but not high (L4) autonomy, are positive and significant, supporting H5.

The present study demonstrates the regulatory and consumer-innovativeness effects on the level of automation at which consumers will adopt AVs. More specifically, it proposes that a promotion focus may strengthen the positive impacts of AV adoption at level 4 and level 5, while a prevention focus has a positive effect on AV adoption at level 3. Moreover, consumer innovativeness related to novelty-seeking has a significantly positive association with AV adoption at level 4, and consumers' independent decision-making results affect the AV adoption at level 5 .

\subsection{Predictive analytics: Neural network and decision tree analysis}

Predictive analytics harness the power of machine learning algorithms to identify the drivers of human behavior (Siegel, 2016). Machine learning refers to the process of a machine's "learning" via computer languages and algorithms that are provided by humans to develop new knowledge about human behavior by feeding on big data. The algorithms that are commonly used in machine learning can be categorized into supervised learning and unsupervised learning. Supervised learning is a machine learning process that maps input onto output, where output can be categories of people like adopters vs. non-adopters of AVs. The most common algorithms of supervised learning include logistic regression, multinomial logit analysis, decision trees, and neural networks. Unsupervised learning, on the other hand, draws inferences from datasets such as categorization. The most common unsupervised learning methods include cluster analysis, which is used to explore 
patterns of groups in data. Common clustering algorithms include $\mathrm{K}$-means clustering and hierarchical clustering.

We conducted neural network analysis using $\mathrm{R}$ software to profile potential adopters of AVs. Before fitting a neural network, one must preprocess data, including normalizing. While there are several methods with which to normalize data, we used the max-min method and scaled the data range within the interval $[0,1]$. We randomly selected 75 percent of the sample as the training data set and used the remaining
25 percent as the test data set. Using the neural net package in $\mathrm{R}$, we formulated a model to predict three adopter categories with independent variables of age, sex, years of driving experience, prevention focus, promotion focus, CNS, and CIDM. The number of hidden layers is a parameter vector that reflects the number of neurons for each hidden later. This training algorithm converged successfully. Figure 2 shows a neural network model with a hidden layer of three simple neurons, the connections between each layer of neurons, the weights on each connection,

〈Figure 2〉 Neural Network Model

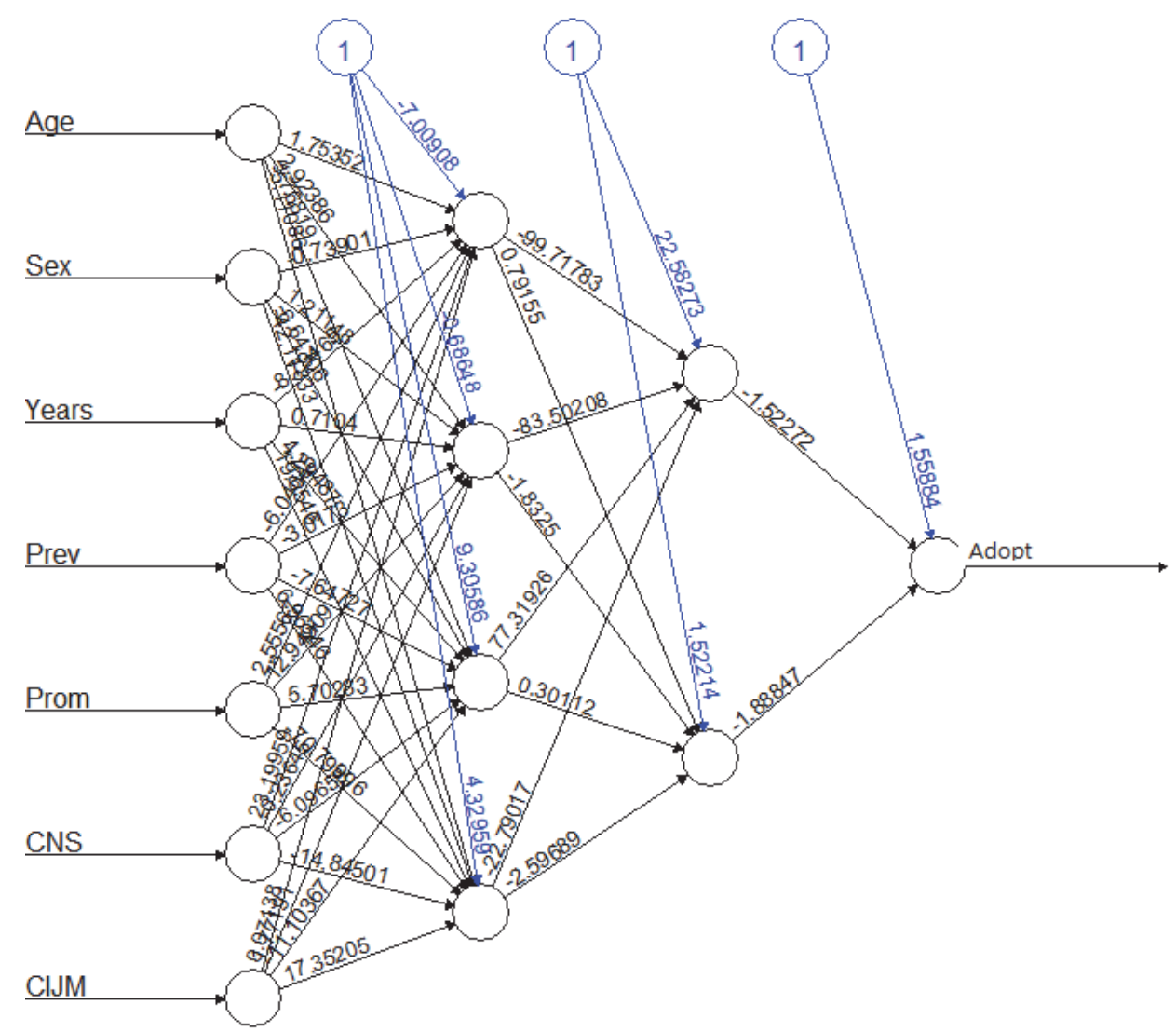

76 ASIA MARKETING JOURNAL Vol. 20 No. 02 July 2018 
and the bias term added in each step. This bias is analogous to the intercept in a linear regression model. The neural network is, in essence, is a black box and one cannot fully interpret the neural network directly. Explaining the outcomes of neural networks is more difficult than is explaining the outcomes of regression models.

To visualize the three adopter profiles, we used decision tree analysis using the R software's rpart package. Figure 3 shows decision trees for categorizing three adopter groups. Here, the decision tree is a simplified representation of classifying individual consumers into three adopter groups. The decision tree is branched into a classification tree, where each internal node is an input feature. Figure 3 shows that those who score high on CIDM, CNS, and promotion focus and who have many years of driving experience are more likely those that will adopt AVs at the full level of automation. The bifurcation decision tree, which classifies adopters separately from non-adopters is presented in Figure 4. Those in the non-adopter category

〈Figure 3〉 Decision Tree Plot for Three Adopter Categories

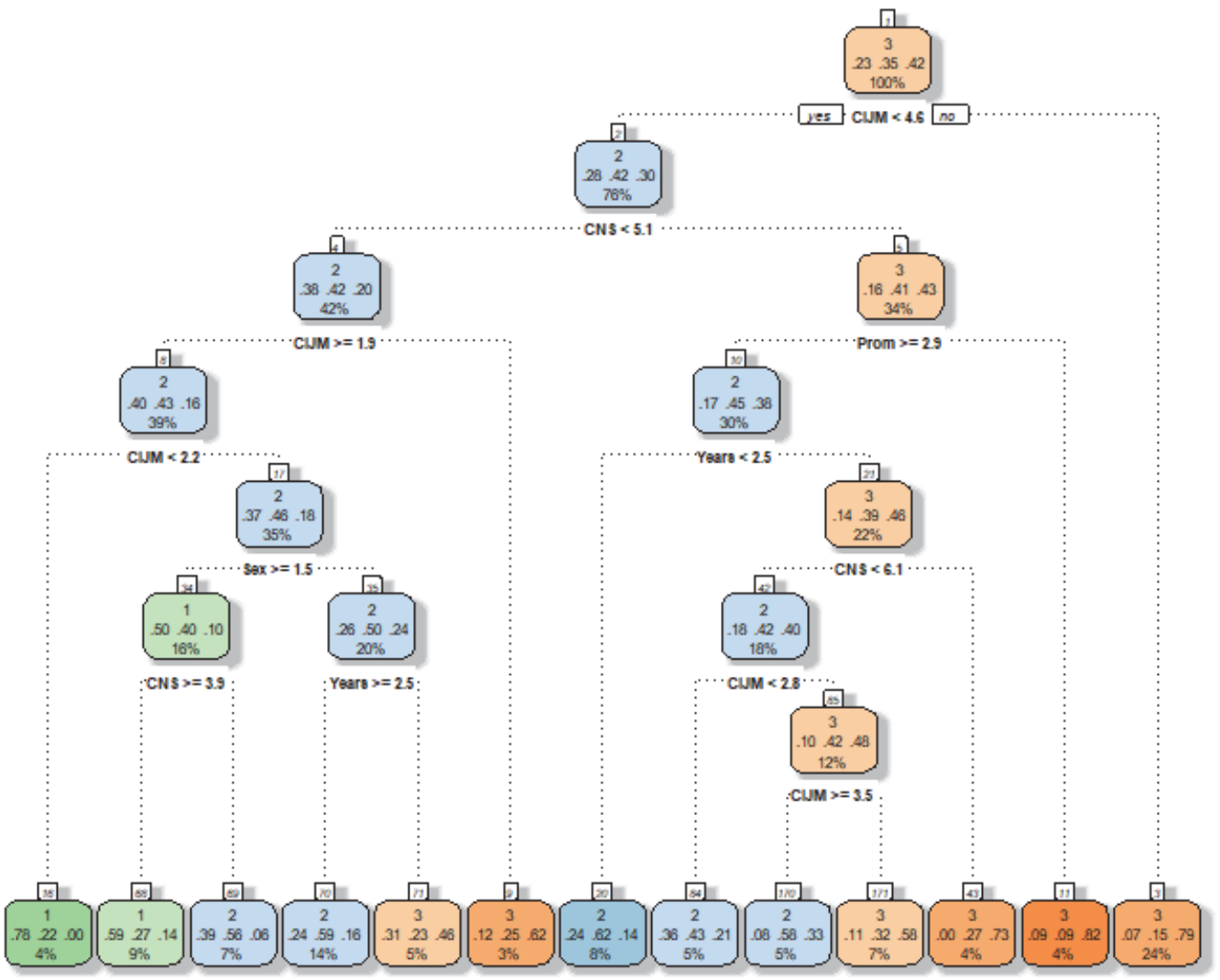

Note: 1: Non-adopters; 2: High-level adopters; 3: Full-level adopters 
〈Figure 4〉 Decision Tree Plot for Adopter vs. Non-Adopter Categories

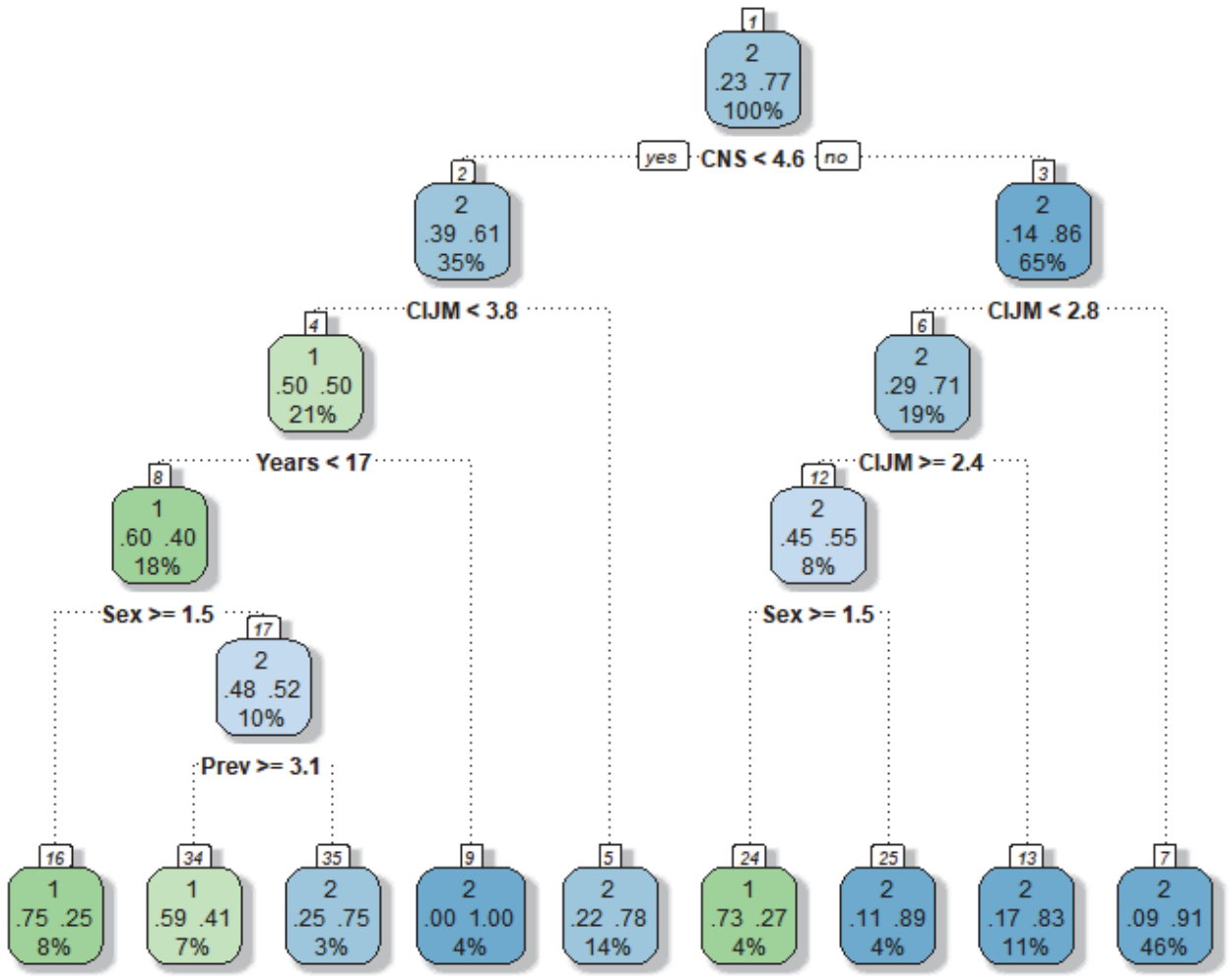

Note: 2: High/Full-level adopters: 1: Non-adopters

include those with low CIDM scores, females, short driving experience, and high prevention scores.

\section{Discussion}

The present research clarifies the association between regulatory focus and consumer innovativeness with AV adoption and clarifies the relationship between the automation levels at which AVs are adopted with WTP for these models. Earlier research in driverless vehicle adoption has highlighted the positive and negative effects of AV adoption and WTP, but those results were contradictory and lacked consumer-level empirical study. This paper sheds new light on these contradictory results by combining the regulatory focus and consumer innovativeness perspectives.

The study has some theoretical and practical implications. First, it contributes to the debate in the regulatory focus literature concerning the distinct effects of promotion and prevention focuses by suggesting that a promotion focus 
is positively associated with acceptance of high and full automation, but a prevention focus plays a vital role in the acceptance of only conditional automation. The model features a comprehensive framework that considers the positive and negative effects of the regulatory focus and shows that acceptance of high levels of vehicle automation is not always associated with a promotion focus. A prevention focus is a more powerful determinant in the decision concerning whether to delegate the driving function to automation. These findings indicate that the benefits of $\mathrm{AV}$ adoption are limited and that consumers may avoid the adverse effects of driverless cars at high levels of automation. These connections generally provide informational benefits for car manufacturers, but some redundant relationships are also useful because these types of relationships allow manufacturers to allocate $R \& D$ investments and resources objectively. When a consumer has never tried an $\mathrm{AV}$, the statistical predictions of possible changes in consumer buying behaviors and decisions after a massive introduction of AVs in human life are supported. These results help to clarify the effects of regulatory focus on the automation level at which AVs are adopted.

The current paper adds a new field of consumer innovativeness to the study of AV adoption by providing consumer-level empirical evidence about the effects of CNS and CIDM on AV adoption. Although much of the consumer innovativeness literature has argued that consumers' innovativeness affects AV adoption, there is a little research on the influences of CNS and CIDM. Building CNS and CIDM structures in AV adoption. Therefore, our results based on CNS and CIJM make significant theoretical and practical contributions by suggesting that CNS enhances AV adoption at the initial stages of automation and CIDM becomes a decisive factor at later levels.

\section{Managerial Implications}

This study proposed that the level of automation at which consumers will adopt AVs is related to the WTP for the appropriate AV level, as the extant literature provides repeated evidence of a positive effect between them. Although most of the empirical studies on WTP and AV adoption have confirmed this positive relationship, the amount of budget required to pay for various levels of automation is diverse, ranging counting from 100 USD to 30,000 USD. The present research avoids such structural misconduct and offers a limited budget to make a fair evaluation of the automation levels at which consumers will adopt AVs. Our findings may be useful in developing marketing strategy when AVs are finally produced en masse. The results on WTP for AVs offer practical implications for car manufacturers, by showing that it is 
not sufficient to develop AVs, which are advantageous in many ways, as the ability to manage consumers' behavior and sentiments related to these innovations is also required.

Identifying how consumers adopt AVs can improve the performance of such technologies for both consumers and producers. The issue of consumer acceptance and adoption has a substantial effect on human lives, economies, business models, the environment, transportation development, and car evolution. Based on predictive analytics, the findings of this study clarify the conditions under which AVs take full advantage of consumers' readiness for such technologies by linking personal needs and goals with driverless car developments. The results suggest that improving innovations in the car industry require not only the effort of manufacturers but also understanding the informational and social benefits that consumers enjoy with AVs.

Besides, the result related to $\mathrm{H} 2$ indicated that in the current, consumers have not fully accepted automatic vehicles, and they are still on the sidelines, especially for highly automated vehicles. Therefore, shortly, technological upgrading of high-level automated vehicles and the elimination of consumer concerns about safety problems are crucial tasks.

\section{Limitations and Future Research Directions}

This research has some limitations that lead to suggestions for future research. First, the differentiation between the levels of $\mathrm{AV}$ automation may not have been entirely clear for online survey respondents. Detailed characteristics of conditional, high, and full automation were designated regarding technical functions only, so they may have been unclear for respondents who had never driven an AV or who do not understand the technical aspects of vehicles. AVs were entirely new to a few respondents, making it necessary to have explained the whole story in person. Second, promotion and prevention focuses are not fixed variables in nature, so the determination of a regulatory focus is highly dependent on human behavior that is irrational and changing with mood, time, and conditions. As current research measures both regulatory focus using a previously developed scale, it does not decide whether a given respondent belongs to a promotion focus or a prevention focus. Third, it future studies could use consumer innovativeness as one of the main factors, thereby exploring more determinants of consumers' willingness to make decisions in favor of innovations than CNS and CIDM alone. The study's findings should also be discussed in examinations of other characteristics that may affect AV adoption. Specifically, future 
research should include the trust factor, which influences almost all characteristics of $\mathrm{AV}$ adoption. Such research should examine consumers' existing trust in the automation of things in life in general and predict the trust in AVs that is necessary to ensure a reasonable level of adoption. Although this study has important theoretical and practical implications, future research should consider other variables like technological development speed, social influence of vehicle users and so on. Finally, studies should be conducted before AVs are fully available in car showrooms so consumers can understand driverless cars and their benefits and avoid their shortcomings and so manufacturers and car dealers can make more proper marketing strategies.

〈Received May 20. 2018〉

〈Accepted July 20. 2018〉

\section{References}

Anderson, J. M., Kalra, N., Stanley, K. D., Sorensen, P., Samaras, C., \& Olumatola, O. A. (2014). Autonomous Vehicle Technology. A Guide for Policymakers. RAND Report. Bansal, P., \& Kockelman, K. M. (2017). Forecasting Americans' long-term adoption of connected and autonomous vehicle technologies. Transportation Research Part A: Policy and Practice, 95, 49-63.
Bansal, P., Kockelman, K. M., \& Singh, A. (2016). Assessing public opinions of and interest in new vehicle technologies: An Austin perspective. Transportation Research Part C: Emerging Technologies, 67, 1-14. Carlson, L., \& Grossbart, S. L. (1984). Toward a better understanding of inherent innovativeness. In R. W. Belk, R. Peterson, G. S. Albaurn, M. B. Holbrook, R. A. Kerin, N. K. Molhotras, \& P. Wright (Eds.), American Marketing Association Educators' Proceedings (Vol. 50, pp. 88-91). Chicago: American Marketing Association.

Casley, S. V., Jardim, A. S., \& Quartulli, A. M. (2013). A study of public acceptance of autonomous cars. Bachelor of Science thesis, Worcester Polytechnic Institute, Worcester, MA, USA.

Craig, S. C., \& Ginter, J. L. (1975). An empirical test of a scale for innovativeness. In M.J. Schlinger (Ed.), Advances in Consumer Research (Vol. 2, pp. 555-562). Ann Arbor, MI: Association for Consumer Research.

Crowe, E., \& Higgins, E. T. (1997). Regulatory focus and strategic inclinations: Promotion and prevention in decision-making. Organizational Behavior and Human Decision Processes, 69, 117-132.

Fagnant, D. J., \& Kockelman, K. (2015). Preparing a nation for autonomous vehicles: Opportunities, barriers and policy recommendations. Transportation Research Part A: Policy and Practice, 77, 167-181. 
Fernandes, P., \& Nunes, U. (2012). Platooning with IVC-enabled autonomous vehicles: Strategies to mitigate communication delays, improve safety and traffic flow. IEEE Transactions on Intelligent Transportation Systems, 13(1), 91-106.

Goldsmith, R. E., \& Hofacker, C. F. (1991). Measuring consumer innovativeness. Journal of Academy of Marketing Science, 19, 209-221.

Gray, J. A. (1990). Brain systems that mediate both emotion and cognition. Cognition and Emotion, 4, 269-288.

Greenblatt, J. B., \& Saxena, S. (2015). Autonomous taxis could greatly reduce greenhouse-gas emissions of US light-duty vehicles. Nature Climate Change, 5(9), 860.

Hevelke, A., \& Nida-Rümelin, J. (2015). Responsibility for crashes of autonomous vehicles: An ethical analysis. Science and Engineering Ethics, 21(3), 619-630.

Higgins, E. T. (1997). Beyond pleasure and pain. American Psychologist, 52, 1280-1300. Higgins, E. T. (1998). Promotion and prevention: Regulatory focus as a motivational principle. Advances in Experimental Social Psychology, $30,1-46$.

Higgins, E. T., Friedman, R. S., Harlow, R. E., Idson, L. C., Ayduk, O. N., \& Taylor, A. (2001). Achievement orientations from subjective histories of success: Promotion pride versus prevention pride. European Journal of Social Psychology, 31, 3-23.
Higgins, E. T., Roney, C., Crowe, E., \& Hymes, C. (1994). Ideal versus ought predilections for approach and avoidance: Distinct selfregulatory systems. Journal of Personality and Social Psychology, 66, 276-286.

Higgins, E. T. (2002). How self regulation creates distinct values: the case of promotion and prevention decision making. Journal of Consumer Psychology, 12(3), 177-191.

Hirschman, E. C. (1980). Innovativeness, novelty seeking, and consumer creativity. Journal of Consumer Research, 7, 283-295.

Hoogma, R., Kemp, R., Schot, J., \& Truffer, B. (2005). Experimenting for Sustainable Transport: The Approach of Strategic Niche Management. Routledge.

Lang, P. J. (1995). The emotion probe: Studies of motivation and attention. American Psychologist, 50, 372-385.

Lin, P. (2016). Why ethics matters for autonomous cars. In Autonomous Driving (pp. 69-85). Springer, Berlin, Heidelberg.

Lockwood, P., Jordan, C. H., \& Kunda, Z. (2002). Motivation by positive and negative role models: Regulatory focus determines who will best inspire us. Journal of Personality and Social Psychology, 83, 854-864.

Manning, K. C., Bearden, W. O., \& Madden, T. J. (1995). Consumer innovativeness and the adoption process. Journal of Consumer Psychology, 4(4), 329-345.

Midgley, D. F., \& Dowling, G. R. (1978). Innovativeness: The concept and its 
measurement. Journal of Consumer Research, 4(4), 229-242.

Mudd, S. (1990). The place of innovativeness in models of the adoption process: An integrative review. Technovation, 10, 119136.

Parasuraman, R., \& Riley, V. A. (1997). Humans and automation: Use, misuse, disuse, abuse. Human Factors, 39(2), 230-253.

Shah, J., Higgins, E. T., \& Friedman, R. S. (1998). Performance incentives and means: How regulatory focus influences goal attainment. Journal of Personality and Social Psychology, 74, 285-293.

Siegel, E. (2016). Predictive Analytics: The power to predict who will click, buy, lie or die. Hoboken, NJ: Wiley.

Stanton, N. A., \& Young, M. S. (1998). Vehicle automation and driving performance. Ergonomics, 41(7), 1014-1028.

Stanton, N. A., Young, M. S., Walker, G. H., Turner, H., \& Randle, S. (2001). Automating the driver's control tasks. International Journal of Cognitive Ergonomics, 5(3), 221-236. Subramanian, S., \& Mittelstaedt, R. A. (1992). Reconceptualizing and measuring consumer innovativeness. In R. P. Leone \& V. Kumar (Eds.), American Marketing Association Educators' Proceedings (Vol. 3, pp. 300-307). Chicago: American Marketing Association. Summerville, A., \& Roese, N. J. (2008). Selfreport measures of individual differences in regulatory focus: A cautionary note. Journal of Research in Personality, 42(1), 247-254.

Werth, L., \& Forester, J. (2007). How regulatory focus influences consumer behavior. European Journal of Social Psychology, 37(1), 33-51. Venkatesh, V., Morris, M. G., \& Ackerman, P. L. (2000). A longitudinal field investigation of gender differences in individual technology adoption decision making processes. Organizational Behavior and Human Decision Processes, 83(1), 33-60. 